\title{
Carbon dioxide versus room air insufflation in colonoscopy: a comparative study
}

\author{
Katlin I Mallette ${ }^{1}$ and Sonny S Dhalla ${ }^{1,2 *}$ \\ ${ }^{1}$ Max Rady College of Medicine, University of Manitoba, Winnipeg, Manitoba, Canada \\ ${ }^{2}$ Gastrointestinal Endoscopy Unit, Brandon Regional Health Centre, Brandon, Manitoba, Canada
}

\begin{abstract}
Background: The uptake of colonoscopy by patients is often limited by the pain and discomfort associated with the procedure. Initial studies demonstrate that carbon dioxide may diminish this discomfort. The objective of this study was to compare carbon dioxide and room air insufflation in colonoscopy with respect to endoscopy time, sedation used, oxygen requirement, post-procedure pain and recovery time.

Methods: Patients who underwent complete colonoscopies by any physician at our facility from November 28, 2014-May 29, 2015, using carbon dioxide or room air were selected. Patient charts were reviewed for patient demographics (BMI, age, gender). Intra-procedure measurements included medication utilized, oxygen requirement and endoscopy time; post-procedure data analyzed was recovery time and presence of pain. Data was analyzed utilizing unpaired t-tests.

Results: Endoscopy time was not increased with the use of $\mathrm{CO}_{2}\left(\mathrm{CO}_{2} 21.5 \mathrm{mins}\right.$, RA 23.0mins, p=0.081, 95\% confidence interval). Oxygen requirement was not significantly changed with the use of $\mathrm{CO}_{2}$. Post procedure recovery time remained unchanged with $\mathrm{CO}_{2}$ compared to air insufflation (59.3mins( $\mathrm{RA}$ ), 61.2mins $\left(\mathrm{CO}_{2}\right)$, p-value $0.225,95 \%$ confidence interval), recovery was also not impacted by the procedure (biopsy vs. polypectomy: $\mathrm{RA}$ : $\mathrm{p}$-value 0.571 ; $\mathrm{CO}$ : $\mathrm{p}$-value 0.138 , $95 \%$ confidence interval). Post-procedure pain was significantly reduced overall, $15 \%$ of patients in the $\mathrm{CO}_{2}$ group compared to $36 \%$ in the $\mathrm{RA}$ group ( $<<0.05,95 \%$ confidence interval).

Conclusion: Carbon dioxide for insufflation reduces the number of patients experiencing post-colonoscopy pain, but does not significantly alter endoscopy time or recovery time for patients.
\end{abstract}

\section{Introduction}

With increasing awareness for colon cancer screening, colonoscopy has become the mainstay in detecting precancerous and cancerous lesions [1]. Currently there are two widely accepted means of insufflation, room air (RA) and carbon dioxide $\left(\mathrm{CO}_{2}\right) \cdot \mathrm{CO}_{2}$ as a means of insufflation in laparoscopic surgery has been used for decades [2]. In endoscopy, the use of $\mathrm{CO}_{2}$, has not been widely used. Majority of the endoscopists continue to utilize RA as supplied by the manufacturer. $\mathrm{CO}_{2}$ insufflation requires additional equipment for its utilization. In a study by Janssens et al. in 2009, less than 5\% of their study respondents utilized $\mathrm{CO}_{2}$ for luminal distention [3], lower than a previous study conducted in the United States, which reported that only $13 \%$ of colonoscopies applied $\mathrm{CO}_{2}$ [4]. A large proportion of those respondents stated that they were either not aware of the ability to use $\mathrm{CO}_{2}$, while others stated challenges in the implementation of equipment [3].

One of the major sources of discomfort for patients undergoing colonoscopy is the volume of gas, leading to abdominal distention and increased pain. Air absorption within the colonic lumen is poor. However, the use of $\mathrm{CO}_{2}$, can lead to quick absorption intraluminally into the blood stream and exhaled [5]. Due to its rapid absorption, it might be logical to assume that a larger volume of $\mathrm{CO}_{2}$ would be required, which may mitigate some of its advantages, yet a study conducted by Bretthauer et al. (2003) indicated that similar volumes of RA and $\mathrm{CO}_{2}$ were utilized by experienced endoscopists [6]. Many studies have demonstrated that the ability of $\mathrm{CO}_{2}$ to be absorbed by the body reduces intra and post procedural abdominal distention [7] and pain [8], which is important for patient compliance in follow up procedures.

The intent of the study was to analyze the effects of $\mathrm{CO}_{2}$ compared to RA insufflation amongst endoscopists at our centre with respect to endoscopy time, sedation required, post-procedure pain and recovery time.

\section{Materials and methods}

\section{Study arms}

Four study arms were utilized for this study. The first of the groupings (scenario 1) compared the cases of the primary endoscopist at our centre (physician A) prior to January $29^{\text {th }}(n=112)$, to the other 6 physicians (physicians B-G) practicing at our facility utilizing RA $(n=114)$. The objective of this arm was to assess the baseline results of all physicians prior to the universal implementation of $\mathrm{CO}_{2}$; this allowed for the detection of inter-practitioner variabilities that may influence the results. The second grouping (scenario 2) consisted

Correspondence to: Sonny S. Dhalla (MD, FRCSC, FACS), Department of General Surgery, Gastrointestinal Endoscopy Unit, Brandon Regional Health Centre 339 Princess Avenue Brandon, Manitoba, Canada R7A 0N7, Tel: 1-204729-3727; Fax: 1-204-728-9535; E-mail: varsity@wcgwave.ca

Key words: Carbon dioxide, room air, insufflation, pain, endoscopy

Received: September 28, 2017; Accepted: October 23, 2017; Published: October 26,2017 
of a comparison between all cases conducted by physician A (prior to Jan $29^{\text {th }} \&$ after Jan $\left.29^{\text {th }}\right)(n=209)$ and all cases conducted by the other 6 physicians (utilizing RA and $\left.\mathrm{CO}_{2}\right)(\mathrm{n}=211)$. Similarly, this scenario was utilized to detect differences in practice between the main endoscopist and the remainder of the physicians, and thus allowed for the assessment of inter-practitioner variability. The third grouping (scenario 3) compared cases of the other 6 physicians utilizing RA $(\mathrm{n}=112)$ versus those that employed $\mathrm{CO}_{2}(\mathrm{n}=118)$; this was used as a direct comparison of RA and $\mathrm{CO}_{2}$ in practitioners who are new to its use. Scenario 3, allowed for the detection of differences, specifically in those who are new to utilizing $\mathrm{CO}_{2}$. The last grouping (scenario 4) compared all cases utilizing $\mathrm{CO}_{2}(\mathrm{n}=333)$ versus all those that utilized RA $(n=112)$, which allowed again for a direct comparison of RA and $\mathrm{CO}_{2}$. However, this scenario was utilized to detect differences between the methods that could be generalized to a broader range of physicians and practices.

\section{Patient selection}

Patients selected underwent complete colonoscopies utilizing either $\mathrm{CO}_{2}$ or RA insufflation in the gastrointestinal department at the Brandon Regional Health Centre, a regional referral centre in Brandon, Manitoba, Canada. Patients completed a standard patient consent form for colonoscopy. The study was reviewed and approved by the Gastrointestinal Endoscopy department administration at Brandon Regional Health Centre. All colonoscopies were scheduled and were performed between November 28, 2014 and May 29, 2015.This regional referral site conducts over 3800 colonoscopies each year; the main endoscopist at this site implemented $\mathrm{CO}_{2}$ into his practice several years ago, however the other physicians only recently began utilizing it for luminal distention on January $29^{\text {th }}$. Physicians included in this study were either general surgeons or gastroenterologists. Physician A and D have greater than 25 years' experience in colonoscopy; physicians' B and $G$ have greater than 20 years' experience; physician $F$ has greater than 15 years, physician $C$ has greater than 10 years and physician $E$ has 3 years' experience in colonoscopy. Consecutive patients were chosen from each of the study arms, defined above, to be representative of the number of patients scoped by each of the physicians over a 1-year period. Table 1 outlines the percentage of total colonoscopies performed by each of the physicians at our site over the most recent year.

\section{Exclusion criteria}

Patients were excluded from the study due to the following: previous large bowel resection, scheduled for endoscopic mucosal resection, incomplete colonoscopy, incomplete recording of data parameters, addition of gastroscopy and those done on an emergent basis.

\section{Parameters assessed}

The charts of all patients selected were reviewed and the required data was extracted and recorded. Patient demographic data was obtained to ensure that all groups were similar with respect to age, gender (male: female ratio) and body mass index (BMI) (calculated utilizing the formula mass/height ${ }^{2}$, where mass is in kilograms and height is in centimeters) (Table 2). It should be noted that both height and weight were self-reported by the patient and were not directly measured by the nurse upon patient admission to the Gastrointestinal Department.
Intra-procedure measurements assessed included amount of sedation utilized, oxygen $\left(\mathrm{O}_{2}\right)$ requirement by nasal prong and endoscopy time. Within the test facility the two medications that are employed for patient sedation during colonoscopies are fentanyl and midazolam. Endoscopy time was measured from the time the scope was introduced, to the time the scope was completely withdrawn.

Post-procedure the patients were assessed for the length of the recovery time and the presence of post procedure pain. For this study, recovery time was defined as the time from admission to the recovery area to time of discharge. The requirements that patients needed to meet prior to discharge were return to pre-procedural baseline of vital signs and sedation/responsiveness. Post-procedure pain was assessed by the nursing staff at three intervals, on admission to recovery, 15 and 30 minutes after admission to recovery. Due to variation in nurse interpretation of pain, for the purposes of this study pain was noted only as present or absent at the intervals.

\section{Data analysis}

Data from all three of the previously mentioned scenarios was analyzed utilizing 2 sample unpaired t-tests on Minitab statistical analysis software by the authors to assess for any differences in means between the two samples involved in each scenario. For each of the scenarios the following parameters were assessed utilizing 2 sample unpaired t-tests: age, gender, BMI, amount of fentanyl and midazolam, $\mathrm{O}_{2}$ requirement, endoscopy time, and recovery time. Post-procedure pain was assessed more thoroughly for each of the scenarios. Pain was assessed in the following ways: overall difference in pain experienced by patients, difference in pain experienced by gender, as well as difference in pain at the assessed time intervals, both overall and by gender.

\section{Results}

\section{Scenario 1}

Patient demographics (BMI, age and gender) (Table 3), and $\mathrm{O}_{2}$ requirement $(3.0 \pm 0.3 \mathrm{~L}$ vs. $3.1 \pm 0.6 \mathrm{~L}$, p-value 0.13$)$ were not significantly different at a confidence interval of 95\% (physician A $\mathrm{n}=112$; physicians $\mathrm{B}-\mathrm{G} \mathrm{n}=114$ ). Endoscopy time was longer in the physician group utilizing RA $(23.13 \pm 5.96 \mathrm{~min}$ vs. $18.91 \pm 8.00 \mathrm{~min}$, $\mathrm{p}<0.001)$. Physician A utilized significantly more midazolam in their patients $(4.01 \pm 1.13 \mathrm{mg}$ vs. $3.16 \pm 0.82 \mathrm{mg}, \mathrm{p}<0.001)$, while physicians B-G utilized significantly more fentanyl in their patients $(79.9 \pm 19.8 \mathrm{mcg}$ vs. $57.6 \pm 16.9 \mathrm{mcg}, \mathrm{p}<0.001)$. The amount of time patients required to recover was not significantly altered between the two groups $(60.7 \pm$ 13.7mins (physician A) vs. $60.4 \pm 16.6$ mins (physicians B-G), p-value 0.86 ) and the time for recovery was not significantly shorter for biopsy when compared to more invasive procedures (Physician A: p-value 0.46) (Physicians B-G: p-value 0.39). Patients of physician A overall had less discomfort ( $13 \%$ vs. $35 \%)$, upon arrival to the recovery area ( $13 \%$ vs. $31 \%$ ), or 15 minutes in to the recovery period ( $4 \%$ vs. $12 \%)$. Both genders experienced less pain overall (males: 17\% vs. $40 \%$ ) (females: $10 \%$ vs. $31 \%$ ) and at admission to recovery (males: $15 \%$ vs. $34 \%$ ) (females: $10 \%$ vs. $28 \%$ ). At 15 minutes in to the recovery period, males had significantly less pain in the $\mathrm{CO}_{2}$ group (4\% vs. 17\%) (Figure 1).

Table 1. Percentage of colonoscopies performed by each of the physicians at our site from April 1, 2014-March 31, 2015.

\begin{tabular}{|c|c|c|c|c|c|c|}
\hline Physician & A & B & C & D & E & F \\
\hline \# Colonoscopies $/$ year & 1023 & 780 & 524 & 156 & 488 & 516 \\
\hline \% of total & $27 \%$ & $20 \%$ & $14 \%$ & $4 \%$ & $13 \%$ & $14 \%$ \\
\hline
\end{tabular}


Table 2. Patient characteristics for all patients included in the study

\begin{tabular}{|c|c|}
\hline Characteristics & Total $(\mathrm{n}=445)$ \\
\hline Age $\left(\mathrm{M}^{*} \pm \mathrm{SD}^{\dagger}\right)$ & $59 \pm 14$ \\
\hline Female $(\%)$ & $222(50 \%)$ \\
\hline Male $(\%)$ & $223(50 \%)$ \\
\hline BMI $(\mathrm{M} \pm \mathrm{SD})$ & $28.7 \pm 5.6$ \\
\hline
\end{tabular}

$* \mathrm{M}$ is the mean

$\uparrow \mathrm{SD}$ is the standard deviation

Table 3. Patient characteristics for scenario 1

\begin{tabular}{|c|c|c|c|}
\hline Characteristics & $\begin{array}{c}\text { Physician A (before } \\
\text { January 29 } \\
(\mathbf{n}=\mathbf{1 1 2})\end{array}$ & $\begin{array}{c}\text { Physicians B-G RA } \\
(\mathbf{n = 1 1 4})\end{array}$ & P-value $^{\ddagger}$ \\
\hline Age $\left(\mathrm{M}^{*} \pm \mathrm{SD}^{\dagger}\right)$ & $58 \pm 16$ & $59 \pm 13$ & 0.87 \\
\hline Female (\%) & $59(53 \%)$ & $61(54 \%)$ & 0.90 \\
\hline Male (\%) & $53(47 \%)$ & $53(46 \%)$ & 0.90 \\
\hline BMI (M $\pm \mathrm{SD})$ & $29.1 \pm 5.6$ & $28.2 \pm 5.7$ & 0.24 \\
\hline
\end{tabular}

* $\mathrm{M}$ is the mean

$\dagger \mathrm{SD}$ is the standard deviation

$\$$ P-values were calculated utilizing an unpaired t-test

\section{Scenario 2}

Patient demographics (BMI, age and gender) (Table 4) and $\mathrm{O}_{2}$ requirement $(3.0 \pm 0.2 \mathrm{~L}$ vs. $3.1 \pm 0.5 \mathrm{~L}, \mathrm{p}$-value 0.07$)$ were not significantly different at a confidence interval of $95 \%$. Endoscopy time was significantly longer in those undergoing evaluations by physicians B-G $(24.24 \pm 9.43 \mathrm{~min}$ vs. $19.41 \pm 6.26 \mathrm{~min}, \mathrm{p}<0.001)$. Patients who underwent scopes performed by physician A received a statistically significantly higher amount of midazolam $(3.92 \pm 1.08 \mathrm{mg}$ vs. 3.18 $\pm 0.92 \mathrm{mg}, \mathrm{p}<0.001)$, while those scoped by physician B-G received significantly more fentanyl (using either RA or $\left.\mathrm{CO}_{2}\right)(79.9 \pm 18.8 \mathrm{mcg}$ vs. $56.0 \pm 17.9 \mathrm{mcg}, \mathrm{p}<0.001$ ). The time patients needed for recovery was not significantly altered between the groups $(60.0 \pm 12.9 \mathrm{mins}$ (Physician A) vs. $61.5 \pm 15.8 \mathrm{mins}$ (Physicians $\mathrm{B}-\mathrm{G}, \mathrm{CO}_{2} \& \mathrm{RA}$ ), p-value 0.28) and when comparing the recovery time for more invasive procedures to biopsy, patients did not require longer recovery time in the more invasive procedures (Physician A: p-value 0.22) (Physicians B-G $\left(\mathrm{CO}_{2}\right.$ \& RA): p-value 0.12). Patients evaluated by physician A experienced less pain overall ( $16 \%$ vs. $24 \%)$, as well as males at 15 minutes after admission to recovery (4\% vs. $11 \%$ ) but no significant difference (at 95\% confidence interval) was observed between the two groups at admission to recovery (15\% vs. $22 \%$ ), 15 minutes after admission to recovery ( $5 \%$ vs. $7 \%$ ) or 30 minutes after admission to recovery $(2 \%$ vs. $2 \%)$. Neither males nor females demonstrated decreased levels of pain overall (males: $18 \%$ vs. $27 \%$ ) (females: $15 \%$ vs. $21 \%$ ), at admission to recovery (males: $16 \%$ vs. $24 \%$ ) (females: $14 \%$ vs. $19 \%$ ), 15 minutes after admission to recovery in females (6\% vs. $4 \%$ ) or 30 minutes after admission to recovery (males: $3 \%$ vs. $5 \%$ ) (females: $2 \%$ vs. $0 \%$ ) (Figure 2).

\section{Scenario 3}

Patient demographics (BMI, age, gender) (Table 5), $\mathrm{O}_{2}$ requirement $\left(\mathrm{CO}_{2} 3.0 \pm 0.2 \mathrm{~L}\right.$ vs RA $3.1 \pm 0.6 \mathrm{~L}, \mathrm{p}$-value 0.08$)$ and endoscopy time $\left(\mathrm{CO}_{2} 25.3 \pm 10.5 \mathrm{~min}\right.$ vs RA $23.0 \pm 8.0 \mathrm{~min}$, p-value 0.07$)$ were not found to be significantly different at the $95 \%$ confidence interval. The amount of midazolam $\left(3.20 \pm 1.02 \mathrm{mg}\left(\mathrm{CO}_{2}\right)\right.$ vs $3.17 \pm 0.82 \mathrm{mg}(\mathrm{RA})$, p-value 0.75$)$ or fentanyl $\left(79.9 \pm 20.5 \mathrm{mcg}\left(\mathrm{CO}_{2}\right)\right.$ vs. $80.2 \pm 16.8 \mathrm{mcg}$ (RA), p-value 0.88 ) utilized were not statistically different between the two groups. The time patients spent in the recovery room was not significantly altered between the two groups $(59.3 \pm 14.4 \mathrm{mins}$ (RA) vs. $63.2 \pm 16.1 \mathrm{mins}\left(\mathrm{CO}_{2}\right)$, p-value 0.05$)$ and when comparing the recovery time in the more invasive procedures to biopsy, patients did not require significantly longer recovery time (RA: p-value 0.57$)\left(\mathrm{CO}_{2}\right.$ : $\mathrm{p}$-value 0.30 ). Patients who received $\mathrm{CO}_{2}$ overall had less pain ( $13 \%$ vs. $\left.36 \%\right)$, when arriving to the recovery room ( $13 \%$ vs. $31 \%)$, and 15 minutes in to the recovery period ( $3 \%$ vs. $13 \%$ ). Both genders experienced less pain overall (males: $16 \%$ vs. $40 \%$ ) (females: $10 \%$ vs. $32 \%$ ) and upon arrival to the recovery area (males: $16 \%$ vs. $35 \%$ ) (females: $10 \%$ vs. $29 \%$ ) (Figure 3 ).

\section{Scenario 4}

Patient demographics (BMI, age, gender) (Table 6), $\mathrm{O}_{2}$ requirement $\left(\mathrm{CO}_{2} 3.0 \pm 0.2 \mathrm{~L}\right.$ vs. RA $3.1 \pm 0.6 \mathrm{~L}$, p-value 0.06$)$ and endoscopy time $\left(\mathrm{CO}_{2} 21.5 \pm 8.5 \mathrm{mins}\right.$ vs. RA $23.0 \pm 8.0 \mathrm{mins}$, p-value 0.08$)$ were not significantly different at a confidence interval of $95 \%$. Patients who underwent scopes with $\mathrm{CO}_{2}$ received higher amounts of midazolam $(3.17 \pm 0.82 \mathrm{mg}$ vs. $3.67 \pm 1.11 \mathrm{mg}, \mathrm{p}<0.001)$, while those who were scoped utilizing RA received more fentanyl $(80.2 \pm 16.8 \mathrm{mcg}$ vs. 64.5 $\pm 22.0 \mathrm{mcg}, \mathrm{p}<0.001)$. The time patients spent in the recovery room was not significantly altered between the two groups $(59.3 \pm 14.4 \mathrm{mins}$ (RA) vs. $61.2 \pm 14.2 \mathrm{mins}\left(\mathrm{CO}_{2}\right)$, p-value 0.23$)$. When comparing the recovery time in more invasive procedures to biopsy, patients did not require significantly longer time for more invasive procedures (RA: p-value 0.57) $\left(\mathrm{CO}_{2}\right.$ : p-value 0.14). Overall patients scoped with $\mathrm{CO}_{2}$ had less pain ( $15 \%$ vs. $36 \%)$, when arriving in the recovery area $(14 \%$ vs. $31 \%$ ), and 15 minutes in to the recovery period ( $4 \%$ vs. $13 \%$ ). Both genders experienced less pain overall (males: 17\% vs. 40\%) (females: $13 \%$ vs. $32 \%$ ) and upon arrival to the recovery area (males: $16 \%$ vs. $34 \%$ ) (females: $12 \%$ vs. $29 \%$ ). At 15 minutes in to the recovery period, males had significantly less pain in the $\mathrm{CO}_{2}$ group (4\% vs. $\left.17 \%\right)$ (Figure 4).

Table 4. Patient characteristics for scenario 2

\begin{tabular}{|c|c|c|c|}
\hline Characteristics & $\begin{array}{c}\text { Physician A } \\
(\mathbf{n}=\mathbf{2 1 5})\end{array}$ & $\begin{array}{c}\text { Physicians B-G } \\
(\mathbf{n = 2 3 1})\end{array}$ & P-value $^{\ddagger}$ \\
\hline Age $\left(\mathrm{M}^{*} \pm \mathrm{SD}^{\dagger}\right)$ & $60 \pm 15$ & $59 \pm 14$ & 0.38 \\
\hline Female (\%) & $103(48 \%)$ & $120(52 \%)$ & 0.50 \\
\hline Male (\%) & $112(52 \%)$ & $111(48 \%)$ & 0.50 \\
\hline BMI (M \pm SD) & $29.2 \pm 5.8$ & $28.4 \pm 5.4$ & 0.14 \\
\hline
\end{tabular}

* $\mathrm{M}$ is the mean

$\uparrow \mathrm{SD}$ is the standard deviation

$\$$ P-values were calculated utilizing an unpaired t-test

Table 5. Patient characteristics for scenario 3

\begin{tabular}{|c|c|c|c|}
\hline Characteristics & $\begin{array}{c}\text { Physicians B-G: RA } \\
(\mathbf{n = 1 1 2})\end{array}$ & $\begin{array}{c}\text { Physicians B-G: } \\
\mathbf{C O}_{\mathbf{2}}(\mathbf{n}=\mathbf{1 1 8})\end{array}$ & P-value $^{\ddagger}$ \\
\hline Age $\left(\mathrm{M}^{*} \pm \mathrm{SD}^{\dagger}\right)$ & $59 \pm 13$ & $58 \pm 15$ & 0.86 \\
\hline Female (\%) & $59(53 \%)$ & $60(51 \%)$ & 0.78 \\
\hline Male (\%) & $53(47 \%)$ & $58(49 \%)$ & 0.78 \\
\hline BMI (M \pm SD) & $28.1 \pm 5.4$ & $28.5 \pm 5.2$ & 0.54 \\
\hline
\end{tabular}

$* \mathrm{M}$ is the mean

$\uparrow \mathrm{SD}$ is the standard deviation

$\$$ P-values were calculated utilizing an unpaired t-test

Table 6. Patient characteristics for scenario 4

\begin{tabular}{|c|c|c|c|}
\hline Characteristics & $\begin{array}{c}\text { All RA } \\
(\mathbf{n = 1 1 2})\end{array}$ & $\begin{array}{c}\text { All CO } \\
(\mathbf{n = 3 3 3})\end{array}$ & P-value $^{\ddagger}$ \\
\hline Age $\left(\mathrm{M}^{*} \pm \mathrm{SD}^{\dagger}\right)$ & $59 \pm 13$ & $59 \pm 15$ & 0.71 \\
\hline Female $(\%)$ & $59(53 \%)$ & $163(49 \%)$ & 0.50 \\
\hline Male $(\%)$ & $53(47 \%)$ & $170(51 \%)$ & 0.50 \\
\hline BMI $(\mathrm{M} \pm \mathrm{SD})$ & $28.1 \pm 5.4$ & $29.0 \pm 5.6$ & 0.15 \\
\hline
\end{tabular}

* $\mathrm{M}$ is the mean

$\uparrow \mathrm{SD}$ is the standard deviation

$\$$ P-values were calculated utilizing an unpaired t-test 


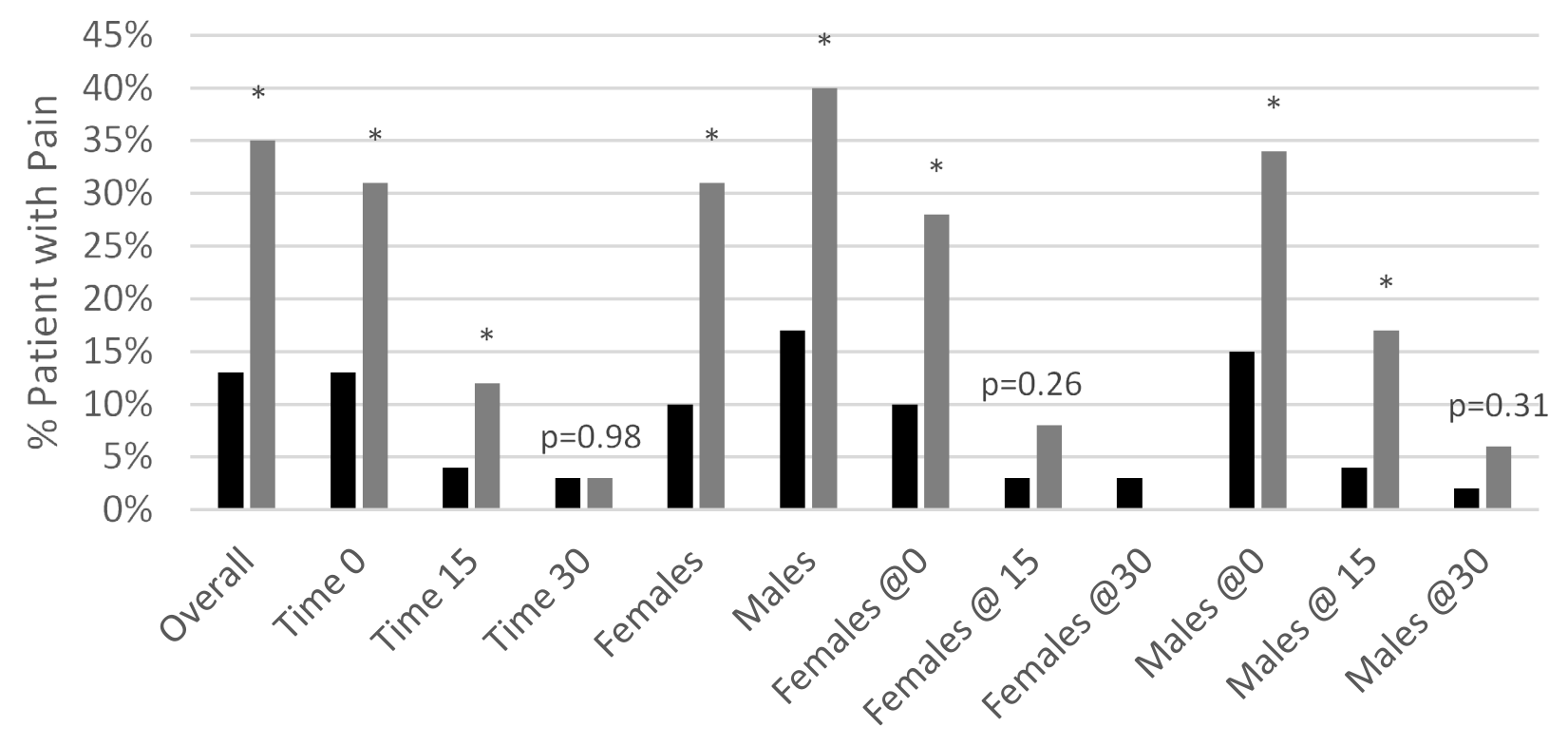

\section{Category}

Physician A Physicians B-G

Figure 1. Post-colonoscopy pain experienced by patients at various time points of recovery for scenario 1 .

* indicates statistical significance at $95 \%$ confidence interval $(\mathrm{p}<0.05)$ utilizing two sample unpaired t-test.

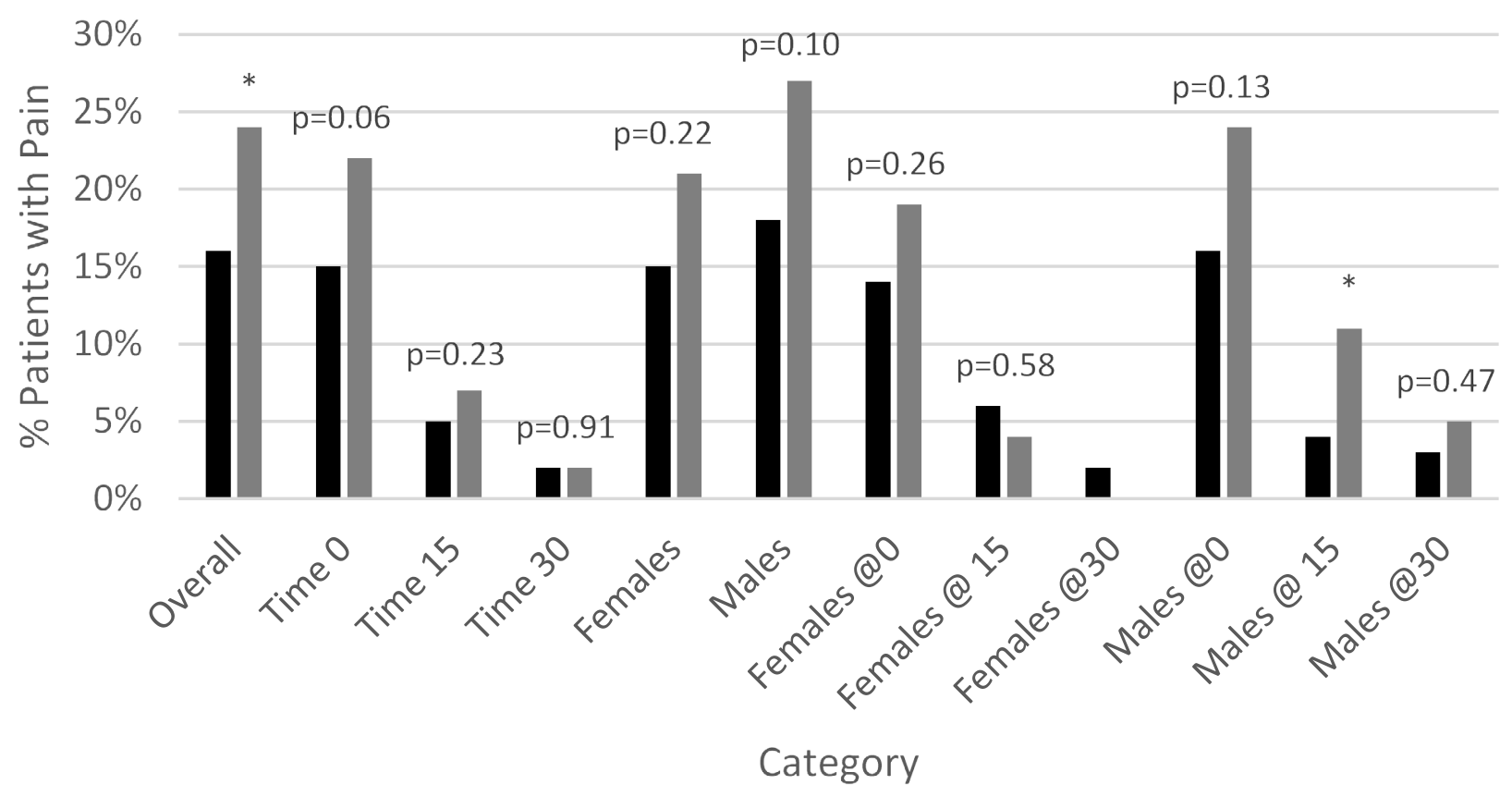

- Physician A Physicians B-G

Figure 2. Post-colonoscopy pain experienced by patients at various time points of recovery for scenario 2

$*$ indicates statistical significance at $95 \%$ confidence interval $(\mathrm{p}<0.05)$ utilizing two sample unpaired $\mathrm{t}$-test. 


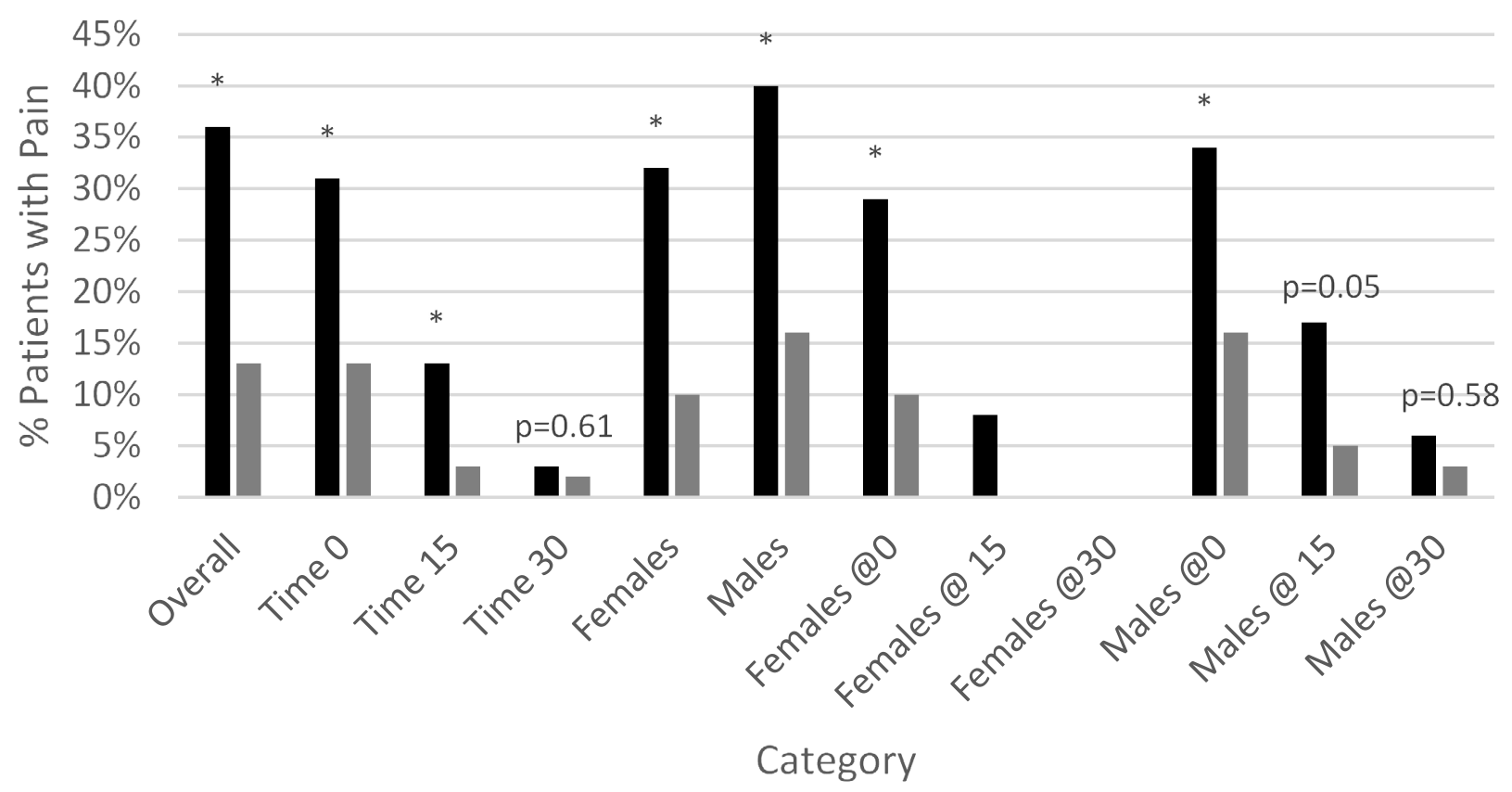

- Room Air a Carbon Dioxide

Figure 3. Post-colonoscopy pain experienced by patients at various time points of recovery for scenario 3 .

* indicates statistical significance at $95 \%$ confidence interval $(\mathrm{p}<0.05)$ utilizing two sample unpaired t-test.

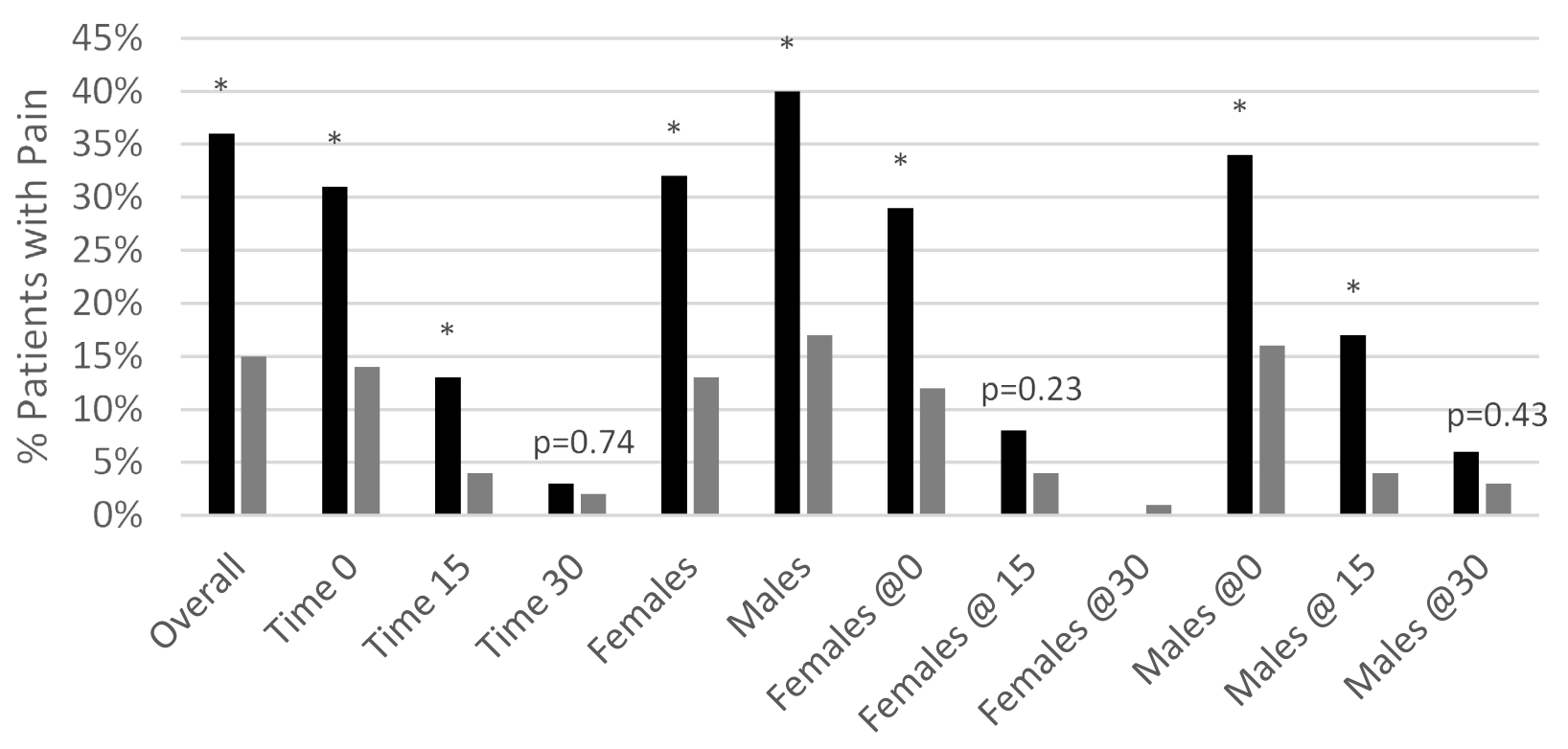

Category

- Room Air Carbon Dioxide

Figure 4. Post-colonoscopy pain experienced by patients at various time points of recovery for scenario 4

* indicates statistical significance at $95 \%$ confidence interval $(\mathrm{p}<0.05)$ utilizing two sample unpaired t-test. 


\section{Discussion}

The use of colonoscopy is the main method of detection of colon polyps and cancer. Many individuals are reluctant to undergo colonoscopy due to their perception of pain associated with the procedure. $\mathrm{CO}_{2}$ has been suggested as a means of reducing patient discomfort for several years [4,5]. A barrier to the implementation of any intervention in health care is the cost of it use. However, $\mathrm{CO}_{2}$ is relatively inexpensive, in a study conducted by Wong et al. in 2008 calculated that its use cost less than 0.84 euros extra per patient when compared to the use of RA [9]. The use of $\mathrm{CO}_{2}$ has also been found to be safe for use with electrosurgical instruments, as such it is a viable method for use in all colonoscopic procedures [10].

Within all scenarios, the patient profile was similar between all groups. Intra-procedure $\mathrm{O}_{2}$ requirement did not change with the introduction of $\mathrm{CO}_{2}$ insufflation, thus indicating that the respiratory drive of patients did not change. $\mathrm{CO}_{2}$ is likely safe in all patients, as $\mathrm{O}_{2}$ requirements were not increased, and patients with chronic lung disease were not excluded. However, the data for end-tidal $\mathrm{CO}_{2}\left(\mathrm{ETCO}_{2}\right)$ was not assessed in this study as it was not readily available on all patients. To confirm these findings, it would be necessary to study the $\mathrm{ETCO}_{2}$ of patients undergoing colonoscopy. Previous studies assessing ETCO $_{2}$ have been mixed with some demonstrating an increase, while others demonstrating no change in levels $[11,12]$.

Endoscopy time was largely dependent on the individual endoscopist. Physicians new to the use of $\mathrm{CO}_{2}$ did not significantly increase their endoscopy time when compared to their baseline. Physicians adapted quickly to the use of $\mathrm{CO}_{2}$ method of insufflation.

The amount of administration of medications appear to be largely physician dependent during the procedure. Some physicians prefer to utilize higher amounts of midazolam, while others prefer fentanyl. The use of $\mathrm{CO}_{2}$ did not alter significantly their prescribing practices, however, the impression by the nursing staff is that physicians utilize less medication with $\mathrm{CO}_{2}$. At our institution, nursing staff are under the impression that patients who underwent colonoscopy with $\mathrm{CO}_{2}$ had shorter recovery times. However, the difference was not significant when analyzing the data. Many confounding factors may have skewed the data, including patients waiting for their family to pick them up, lab work that needed to be completed or waiting to speak with their endoscopist. Discharge criteria utilized by the unit was not altered after the implementation of $\mathrm{CO}_{2}$. Some nursing staff were still waiting for patients to pass flatus and were monitoring for bowel sounds. As $\mathrm{CO}_{2}$ is readily absorbed into the bloodstream and expired, these criteria may no longer be appropriate. There was no difference in recovery time between patients undergoing colonoscopy with or without biopsy versus polypectomy. A difference in recovery time was also postulated by Belle et al., but they were also unable to detect a difference in their study [7]. They attributed this inconsistency to differences between clinical assessment done by nursing staff and guidelines [7].

Overall, pain was improved with the use of $\mathrm{CO}_{2}$. This can be explained by the mechanism of clearance of the $\mathrm{CO}_{2}$, as it can be rapidly absorbed which means less abdominal distention and thus less discomfort. A study conducted by Belle et al., demonstrated less abdominal distention with $\mathrm{CO}_{2}$ by measuring abdominal girth before and after colonoscopy [7]. Similarly, two randomized control trials demonstrated minimal colonic gas in the large intestine was discovered by abdominal radiograph 1-hour post-procedure with $\mathrm{CO}_{2}\left(94 \% \mathrm{CO}_{2}\right.$ vs. $2 \% \mathrm{RA})$, and minimal residual gas in the small intestine $\left(87 \% \mathrm{CO}_{2}\right.$ vs. $55 \%$ RA) $[13,14]$. In our study, significantly less patients experienced pain at 15 minutes in to recovery, but at 30 minutes this difference did not reach statistical significance. Studies have demonstrated that the benefits of $\mathrm{CO}_{2}$ with respect to pain can last from 6 to 24 hours $[8,15]$. Matyja et al. found that $\mathrm{CO}_{2}$ in unsedated colonoscopy did not reduce pain immediately or 15 minutes after the procedure, but a slightly lower pain intensity was observed 60 minutes after the procedure, although did not reach statistical significance [16]. Procedures conducted in their study were also very short (an average of 11 minutes each), postulating that in shorter procedures the use of $\mathrm{CO}_{2}$ did not impact the post-procedure pain [16].

Overall decreased pain is seen in both genders in those undergoing colonoscopy with $\mathrm{CO}_{2}$. The level of physician experience is an important factor in predicting patient discomfort, with patients experiencing less pain during and after the procedure was noted in our study.

\section{Limitations}

Due to the small sample size and ability to measure pain, which is subjective in nature, the extent of the benefits of $\mathrm{CO}_{2}$ over RA insufflation in post-procedure discomfort are difficult to assign a metric especially in a sedated patient with different indications for colonoscopy. Data from multiple endoscopists, with different skill sets and training, were included which may have influenced the outcomes. Lastly, as data was collected from charts, data directly from the patients could not be obtained.

\section{Future directions}

Further studies should focus on assessing the extent to which pain is decreased in patients when $\mathrm{CO}_{2}$ is utilized, as well as to investigate intra-procedure discomfort experienced by patients. The advantage of $\mathrm{CO}_{2}$ should also be assessed in gastroscopy and endoscopic retrograde cholangiopancreatography.

\section{Conclusion}

Data obtained in this study suggests that utilizing $\mathrm{CO}_{2}$ for insufflation leads to a better overall patient experience, with less discomfort during and after the procedure. With less discomfort, patients may be more likely to present for follow up procedures, furthermore cost saving could be realized with earlier discharge as suggested by clinical impression from nursing staff. It also suggests that physicians do not need to significantly change their practice, with respect to medication administration and endoscopy time.

\section{Author contributions}

Both authors contributed equally to following: conception and design; analysis and interpretation of the data; drafting of the article; critical revision and final approval of the article

\section{Acknowledgements}

The authors thank all members of the endoscopy department at Brandon Regional Health Centre, the Office of Rural and Northern Health, and Prairie Mountain Health.

\section{Source of funding}

None declared.

\section{Competing interests:}

None declared. 


\section{References}

1. Seeff LC, Richards TB, Shapiro JA (2004) How many endoscopies are performed for colorectal cancer screening? Results from CDC's survey of endoscopic capacity. Gastroenterology 127: 1670-1677. [Crossref]

2. Nakajima K, Lee SW, Sonoda T (2005) Intraoperative carbon dioxide colonoscopy: a safe insufflation alternative for locating colonic lesions during laparoscopic surgery. Surg Endosc 19: 321-325. [Crossref]

3. Janssens F (2009) Carbon dioxide for gut distension during digestive endoscopy: Technique and practice survey. World J Gastroenterol 15: 1475. [Crossref]

4. Phaosawasdi K, Cooley W, Wheeler J (1986) Carbon dioxide-insufflated colonoscopy: an ignored superior technique. Gastrointest Endosc 32: 330-333. [Crossref]

5. Hussein AMJ, Bartram CI, Williams CB (1984) Carbon dioxide insufflation for more comfortable colonoscopy. Gastrointest Endosc 30: 68-70. [Crossref]

6. Bretthauer M, Hoff GS, Thiis-Evensen E (2003) Air and carbon dioxide volumes insufflated during colonoscopy. Gastrointest Endosc 58: 203-206. [Crossref]

7. Chen YJ, Lee J, Puryear M (2014) A randomized controlled study comparing room air with carbon dioxide for abdominal pain, distention, and recovery time in patients undergoing colonoscopy. Gastroenterol Nurs 37: 273-278. [Crossref]

8. Wang WL, Wu ZH, Sun Q (2012) Meta-analysis: the use of carbon dioxide insufflation vs. room air insufflation for gastrointestinal endoscopy. Aliment Pharmacol Ther 35: 1145-1154. [Crossref]
9. Wong JC, Yau KK, Cheung HY (2008) Towards painless colonoscopy: a randomized controlled trial on carbon dioxide-insufflating colonoscopy. ANZ J Surg 78: 871-874. [Crossref]

10. Gerald Rogers BH (1974) The safety of carbon dioxide insufflation during colonoscopic electrosurgical polypectomy. Gastrointest Endosc 20: 115-117. [Crossref]

11. Bretthauer M, Thiis-Evensen E, Huppertz-Hauss G (2002) NORCCAP (Norwegian colorectal cancer prevention): a randomised trial to assess the safety and efficacy of carbon dioxide versus air insufflation in colonoscopy. Gut 50: 604. [Crossref]

12. Singh R, Neo EN, Nordeen N (2012) Carbon dioxide insufflation during colonoscopy in deeply sedated patients. World J Gastroenterol 18: 3250-3253. [Crossref]

13. Sumanac K, Zealley I, Fox BM (2002) Minimizing postcolonoscopy abdominal pain by using $\mathrm{CO}$ insufflation: A prospective, randomized, double blind, controlled trial evaluating a new commercially available $\mathrm{CO}$ delivery system. Gastrointest Endosc 56: 190-194. [Crossref]

14. Stevenson GW, Wilson JA, Wilkinson J (1992) Pain following colonoscopy: elimination with carbon dioxide. Gastrointest Endosc 38: 564-567. [Crossref]

15. Díez-Redondo P, Gil-Simón P, Alcaide-Suárez N, Atienza-Sánchez R, Barrio-Andrés J, et al. (2012) Comparison between insufflation with air or carbon dioxide during the colonoscopy in sedated patients with propofol. Rev Esp Enferm Dig 104: 411-417. [Crossref]

16. Szura M, Pach R, Matyja A, Kulig J (2015) Carbon dioxide insufflation during screening unsedated colonoscopy: a randomised clinical trial. Eur J Cancer Prev 24: 37-43. [Crossref]

Copyright: $\odot 2017$ Mallette KI. This is an open-access article distributed under the terms of the Creative Commons Attribution License, which permits unrestricted use, distribution, and reproduction in any medium, provided the original author and source are credited. 